\title{
Prevalence of HSV1/2 Congenital Infection Assessed Through Genome Detection on Dried Blood Spot in Individuals with Autism Spectrum Disorders
}

\author{
EMANUELA ZAPPULO ${ }^{1}$, MARIA PIA RICCIO ${ }^{2}$, SANDRO BINDA $^{3}$, LAURA PELLEGRINELLI $^{3}$, \\ FABRIZIO PREGLIASCO ${ }^{3}$, ANTONIO RICCARDO BUONOMO ${ }^{1}$, BIAGIO PINCHERA ${ }^{1}$, \\ GIORDANO D’URSO ${ }^{4}$, CARMELA BRAVACCIO ${ }^{2}$, GUGLIELMO BORGIA ${ }^{1}$ and IVAN GENTILE ${ }^{1}$ \\ ${ }^{1}$ Section of Infectious Diseases, Department of Clinical Medicine and Surgery, \\ ${ }^{2}$ Department of Medical Translational Science, and ${ }^{4}$ Section of Psychiatry, Department of Neurosciences, \\ Reproductive and Odontostomatological Sciences, Federico II University of Naples, Naples, Italy; \\ ${ }^{3}$ Department of Biomedical Sciences for Health, University of Milan, Milan, Italy
}

\begin{abstract}
Background/Aim: Etiopathogenesis of autism spectrum disorders (ASD) remains to be elucidated. Congenital infections, particularly viral infections, have repeatedly been associated with the onset of such disorders. Our study aimed at assessing the prevalence of herpes simplex type 1 and 2 (HSVI/2) congenital infections in patients with ASD. Materials and Methods: In our casecontrol study, a total of 38 children with ASD were compared to 44 age- and sex-matched controls regarding the presence of HSVI/2 infection though viral DNA polymerase chain reaction performed on dried blood spots collected at birth. Results: No HSV congenital infection was detected in either group. Conclusion: Our negative finding is in agreement with other studies that failed to demonstrate a definitive role of HSV on the onset of ASD. Further investigation of congenital HSV prevalence in larger and more powerful studies is needed to undeniably discard a role of such virus in the etiopathogenesis of ASD.
\end{abstract}

The autism spectrum disorders (ASD) are a range of developmental disorders defined by a deficit in social interaction, and a narrow and repetitive pattern of interests, behavior and activities (1). It is estimated that the prevalence

This article is freely accessible online.

Correspondence to: Emanuela Zappulo, Department of Clinical Medicine and Surgery-Section of Infectious Diseases - Federico II University of Naples, via S. Pansini 5, 80131 Naples, Italy. Tel: +39 0817463178, Fax +39 0817463094, e-mail: e.zappulo@gmail.com

Key Words: Herpes simplex, neonatal herpes, neurobiology, DBS, etiology. of ASD is increasing, having reached about $1.5 \%$ in developed countries, with a male-female ratio of 4:1 (2).

Only in a minority of cases, is a definite etiology identified (e.g. fragile $\mathrm{X}$ syndrome, neurofibromatosis, tuberous sclerosis, Timothy syndrome, exposure to thalidomide) (3-5). The majority of ASD cases (about 85\%) are defined as idiopathic (i.e. without a definite etiological agent) (6). In these cases, it is generically said that it derives from an interaction between genetic and environmental factors. Consequently, in the absence of a causative agent, no preventative measure nor etiological treatment is available for ASD.

However, recent studies have demonstrated that some core symptoms of ASD can be selectively targeted using neuromodulation treatments, such as transcranial direct current stimulation (7), a technique which has already been proven to be effective in other neuropsychiatric disorders possibly arising in childhood, such as depression (8) and obsessive-compulsive disorder (9).

In an attempt to identify the etiological agents of ASD, several studies have been carried out to evaluate a role of infections (10-12), but none of these provided definite conclusions.

Our group has proposed that ASD (or at least some cases) may be due to a deranged immune response in children with a genetic and environmental/lifestyle (e.g. vitamin D deficit)induced susceptibility to autoimmunity which is triggered by a viral infection and leads to the impairment of specific areas in the central nervous system (13).

Some authors have reported clinical cases of congenital herpes simplex virus (HSV) infection in patients diagnosed with ASD $(14,15)$. A few studies evaluated the prevalence of antibodies to HSV in children with ASD but obtained discordant results $(16,17)$. 
All the studies performed so far evaluated specific antibody prevalence in individuals with ASD. However, this type of study does not allow the time-point of contact between the virus and the patient to be specified. Moreover, several studies have pointed out that a key point in ASD development is during intrauterine life or at birth $(2,13)$. Investigation of dried blood spot (DBS) in viral disease management has found several applications and DBS routinely collected at birth allow the diagnoses of viral congenital infection even years later. Previously, analysis of HSV DNA in DBS has been evaluated in retrospectively studies, showing a highly diagnostic concordance with standard testing and a limit of detection comparable to that of cytomegalovirus DNA in DBS $(18,19)$. The aim of this study was to evaluate the rate of congenital HSV1 and -2 infection assessed via detection of viral genome in DBS by polymerase chain reaction (PCR) in children with ASD and healthy controls.

\section{Materials and Methods}

Patients. Patients admitted to the Child and Adolescent Neuropsychiatry Unit at the Second University of Naples and to the Department of Pediatrics at the Federico II University of Naples between January 2010 and January 2013 were enrolled. Informed consent was obtained from children's parents or from authorized representatives. The Ethics Committee of the Federico II University of Naples approved the study (protocol number: 85/09). Inclusion criteria for cases were diagnosis of ASD according to the Diagnostic and Statistical Manual of Mental Disorders, Fourth edition, Text Revision (DSM-IV-TR) (20) and confirmed by DSM-5 criteria; individuals were excluded if their parents/representative were unable or unwilling to sign the informed consent form.

Controls were recruited at the Division of Pediatric Surgery of Federico II University where they were admitted for minor surgical treatments, or at a general pediatrician in Torre del Greco, Naples, Italy where they went for routine check-up. All controls underwent an interview to rule out any possible neuropsychiatric disorder.

Neuropsychiatric evaluation. A skilled clinician administered Griffiths Mental Development Scales (GMDS-ER) (17) and a revised algorithm of Autism Diagnostic Observation Schedule (ADOS) (18-20) to all cases. Patients' parents or guardians underwent an Autism Diagnostic Interview, Revised version (ADIR) (21), Childhood Autism Rating Scales (CARS) (22) and Vineland Adaptive Behaviour Scales (VABS) (23).

The evaluation allowed three groups of patients to be identified based on ASD severity, defined according to DSM-5 criteria as specified below: Level 1 (individuals that need support to have adequate adaptation), Level (individuals that need significant support to have adequate adaptation), Level 3 (individuals that need very significant support to have an adequate adaptation).

Specific congenital disorders are screened in Italy through blood collection as DBS. Screening is carried out on every newborn at 25 days of age and specimens are stored at room temperature and are not exposed to light.
Table I. Main clinical scores of children with autism spectrum disorders. Data are given as median and interquartile range.

\begin{tabular}{lc}
\hline Scale & Score \\
\hline GMDS (Developmental quotient) & $50(43-59)$ \\
VABS (Adaptive quotient) & $50(38-58)$ \\
ADOS (Language) & $5(4-6)$ \\
ADOS (Interaction) & $11(8-12)$ \\
ADOS (Total score) & $16(13-18)$ \\
CARS (Total score) & $36(33-40)$ \\
\hline
\end{tabular}

GMDS: Griffith Mental Developmental Scales; VABS: Vineland Adaptive Behavior Scales; ADOS: Autism Diagnostic Observation Schedule; CARS: Childhood Autism Rating Scales.

Virological tests. To analyze viral DNA in DBS, one spot was punched manually into $35 \mu \mathrm{l}$ of Minimum Essential Medium. Each spot measured $3 \mathrm{~mm}$ in diameter, corresponding with approximately $5 \mu \mathrm{l}$ dried blood. For each patient, three spots were with utilized to guarantee triplicate analyses. DNA was extracted by heat treatment; following 1-hour incubation at $55^{\circ} \mathrm{C}$, samples were kept at $100^{\circ} \mathrm{C}$ for $7 \mathrm{~min}$ and were then spun at $11,200 \times g$ in order to clarify the supernatants, which were then frozen at $-80^{\circ} \mathrm{C}$ overnight (21). To confirm DNA extraction from DBS, a house-keeping gene was amplified with a PCR designed to target human $\beta$-globin with primers $\mathrm{GH} 20$ and $\mathrm{PCO} 4$ (22). If human $\beta$-globin was detected from DBS, the following test on HSV-DNA was carried out; otherwise, the whole extraction process was repeated. DNA of HSV1 and HSV2 was amplified using nested-PCR targeting a region in the glycoprotein D and one in the glycoprotein G gene of HSV1 and HSV2, respectively (23). The products of nested-PCR were recognized by agarose $(2 \%)$ gel electrophoresis.

A patient was considered positive for HSV1/2 when at least two out of the three tests were positive for HSV-DNA, whereas if only one of the three tests was positive, a new series of punches were repeated from the DBS. Negative and positive controls for HSV were included in all nested-PCR runs. To avoid cross-contamination, strictly controlled measures were followed: the punch was washed with ethanol and flamed between one DBS punch and the next; moreover, after the 3-series spots were taken from one patient, punching from unsoiled paper was performed as a negative control throughout the study series.

Statistical analysis. Kolmogorov-Smirnov test was applied to quantitative continuous variables to assess for Gaussian distribution. If this was the case, data are presented as the mean \pm standard deviation (SD). Data distributed in a non-Gaussian fashion are given as the median and interquartile range (IQR). The same form of presentation was used for non-continuous quantitative variables (e.g. neuropsychiatric severity scores). Student's $t$-test was used for unpaired variables and MannWhitney $U$-test for comparison of Gaussian or non-Gaussian distributed quantitative variables, respectively. For comparison of qualitative variables, the chi-squared test (or Fisher's exact test if appropriate) was used. Statistical analysis was performed using the Statistical Package for the Social Sciences version 18.0 (SPSS Inc. Chicago, IL, USA). 


\section{Results}

A total of 82 children (38 with ASD and 44 healthy controls) were and evaluated. Main demographic and clinical features of children with ASD are reported in Table I. The mean age of children with ASD was higher than that of controls $(5 \pm 1.3$ years $v s .4 \pm 1.7$ years, respectively, $p=0.007)$. The male/female ratio was similar in cases and in controls $(76.3 \% \mathrm{vs} .68 .2 \%$, $p=0.414)$.

Children with ASD had the following median gravity scores: ADOS total score $17 \quad(\mathrm{IQR}=15-20)$, GMDS (Developmental quotient) 54 (IQR =35-62), VABS (Adaptive quotient) 51 (IQR=40-63), CARS total score 37 (IQR=33$40)$. Most patients had a gravity score of $3(55 \%)$, whereas $35 \%$ had a gravity score of 2 and $10 \%$ of 1 .

No DBS in the two cohorts was positive for HSV1 or HSV2 DNA.

\section{Discussion}

Our study shows that no children with ASD as well as none of the controls had a congenital HSV1 or 2 infection as assessed through viral genome detection on DBS collected at birth.

Notably, the interval between the sampling and onset of illness is the most important factor for a positive result of an HSV-DNA assay. A retrospective study led on DBS from 28 children with neonatal HSV infection showed that viremia may be present up to 5 days before and 6 days after the onset of neonatal herpes (19). It has been hypothesized that a child with disseminated disease and shorter incubation time more often has an HSV-DNA-positive DBS card than a child with later onset of symptoms (often encephalitis): this finding may support the role of the neuronal route of transmission in such later onset disease. In previous serological studies, DBS were compared with serum samples and comparable specificity and sensitivity were obtained, and more than one group of researchers had validated the use of DBS for both HSV antibody and DNA detection $(18,19,24)$.

Our negative finding is in agreement with other studies which, using different methods, came to the same conclusion: no role of HSV is currently demonstrated in the etiology of ASD $(16,25)$. We previously showed that children with ASD had a similar anti-HSV rate compared to healthy same-aged controls (25).

However, biological plausibility of HSV as an agent of neurocognitive disorders does exist. In fact, belonging to the Herpesviridae family, this virus therefore has a tropism for the central nervous system. Moreover, these viruses are suspected to act as triggers of a series of autoimmune disorders as they can interact with the immune system (26-28).

Mora et al. found a higher rate of anti-HSV IgM in children with ASD than in healthy controls (17). Moreover, a recent study conducted in Norway found that high levels of HSV-2 IgG antibodies collected in maternal midpregnancy plasma were associated with increased risk of ASD in male offspring (29).

We acknowledge that our study has the following main limitations: i) the small sample size does not allow for a conclusive answer to be given to the question of a possible role of HSV even only in a subset of patients with ASD, as HSV congenital infection is rare [between 1.6 and 60 per 100,000 live births in the general population (30)] and therefore an etiological role of HSV cannot be completely excluded in some cases; ii) the virus could act via 'a hit and run' strategy and therefore it could have triggered a cascade of events during intrauterine life irrespectively of its undetectability at birth. In this light, a recent study found that HSV1 interacts and modifies the expression of several human genes such that it creates a host/pathogen 'interactome' of 1,347 genes (31). These genes might be involved in modulating the risk of several diseases such as schizophrenia or autism (31).

In conclusion, rate of congenital HSV infection assessed through viral genome detection on DBS collected at birth was found to be zero in a small cohort of patients with ASD. However, the biological plausibility of HSV as an agent of neurocognitive disorders exists. Larger and more powerful studies are needed in order to evaluate the reliability of these findings and definitely discard a role of HSV in the etiology of ASD.

\section{Conflicts of Interest}

All Authors confirm that they have no commercial associations that might pose a conflict of interest in connection with the submitted article.

\section{References}

1 American Psychiatric Association: Diagnostic and Statistical Manual of Mental Disorders (5th Ed.). Washington, DC, 2013.

2 Lyall K, Croen L, Daniels J, Fallin MD, Ladd-Acosta C, Lee BK, Park BY, Snyder NW, Schendel D, Volk H, Windham GC and Newschaffer C: The changing epidemiology of autism spectrum disorders. Annu Rev Public Health 38: 81-102, 2017.

3 Benvenuto A, Moavero R, Alessandrelli R, Manzi B and Curatolo P: Syndromic autism: Causes and pathogenetic pathways. World J Pediatr 5(3): 169-176, 2009.

4 Lintas C, Altieri L, Lombardi F, Sacco R and Persico AM: Association of autism with polyomavirus infection in postmortem brains. J Neurovirol 16(2): 141-149, 2010.

5 Devlin B and Scherer SW: Genetic architecture in autism spectrum disorder. Curr Opin Genet Dev 22(3): 229-237, 2012.

6 Autism and Developmental Disabilities Monitoring Network Surveillance Year 2008 Principal Investigators and Centers for Disease Control and Prevention: Prevalence of autism spectrum disorders-autism and developmental disabilities monitoring network, 14 sites, United States, 2008. MMWR Surveill Summ 61(3): 1-19, 2012. 
7 D'Urso G, Bruzzese D, Ferrucci R, Priori A, Pascotto A, Galderisi S, Altamura AC and Bravaccio C: Transcranial direct current stimulation for hyperactivity and noncompliance in autistic disorder. World J Biol Psychiatry 16(5): 361-366, 2015.

8 D’Urso G, Dell'Osso B, Rossi R, Brunoni AR, Bortolomasi M, Ferrucci R, Priori A, de Bartolomeis A and Altamura AC: Clinical predictors of acute response to transcranial direct current stimulation (tDCS) in major depression. J Affect Disord 219: 25-30, 2017.

9 D'Urso G, Brunoni AR, Mazzaferro MP, Anastasia A, de Bartolomeis A and Mantovani A: Transcranial direct current stimulation for obsessive-compulsive disorder: A randomized, controlled, partial crossover trial. Depress Anxiety 33(12): 11321140,2016

10 Libbey JE, Sweeten TL, McMahon WM and Fujinami RS: Autistic disorder and viral infections. J Neurovirol 11(1): 1-10, 2005.

11 Garbett KA, Hsiao EY, Kalman S, Patterson PH and Mirnics K: Effects of maternal immune activation on gene expression patterns in the fetal brain. Transl Psychiatry 2: e98, 2012.

12 Singh VK, Lin SX, Newell E and Nelson C: Abnormal measlesmumps-rubella antibodies and CNS autoimmunity in children with autism. J Biomed Sci 9(4): 359-364, 2002.

13 Gentile I, Zappulo E, Militerni R, Pascotto A, Borgia G and Bravaccio C: Etiopathogenesis of autism spectrum disorders: Fitting the pieces of the puzzle together. Med Hypotheses 81(1): 26-35, 2013.

14 Ghaziuddin M, Tsai LY, Eilers L and Ghaziuddin N: Brief report: Autism and herpes simplex encephalitis. J Autism Dev Disord 22(1): 107-113, 1992.

15 Gillberg C: Onset at age 14 of a typical autistic syndrome. A case report of a girl with herpes simplex encephalitis. J Autism Dev Disord 16(3): 369-375, 1986.

16 Sylvester J O, Vejlsgaard G V and Faber V B: Herpes simplex virus (HSV) antibodies in child psychiatric patients and normal children. Acta Psychiatr Scand 66(1): 42-49, 1982.

17 Mora M, Quintero L, Cardenas R, Suarez-Roca H, Zavala M and Montiel N: [association between HSV-2 infection and serum anti-rat brain antibodies in patients with autism]. Invest Clin 50(3): 315-326, 2009.

18 Barbi M, Binda S, Primache V, Tettamanti A, Negri C and Brambilla C: Use of Guthrie cards for the early diagnosis of neonatal herpes simplex virus disease. Pediatr Infect Dis J 17(3): 251-252, 1998.

19 Lewensohn-Fuchs I, Osterwall P, Forsgren M and Malm G: Detection of herpes simplex virus DNA in dried blood spots making a retrospective diagnosis possible. J Clin Virol 26(1): 39-48, 2003

20 American Psychiatric Association: Diagnostic and Statistical Manual of Mental Disorders. Fourth Edition, Text Revision. American Psychiatric Association: Washington, DC, 2000.
21 Barbi M, Binda S and Caroppo S: Diagnosis of congenital CMV infection via dried blood spots. Rev Med Virol 16(6): 385-392, 2006.

22 Bauer HM, Ting Y, Greer CE, Chambers JC, Tashiro CJ, Chimera J, Reingold A and Manos MM: Genital human papillomavirus infection in female university students as determined by a PCRbased method. JAMA 265(4): 472-477, 1991.

23 Aurelius E, Johansson B, Skoldenberg B and Forsgren M: Encephalitis in immunocompetent patients due to herpes simplex virus type 1 or 2 as determined by type-specific polymerase chain reaction and antibody assays of cerebrospinal fluid. J Med Virol 39(3): 179-186, 1993.

24 Sgaier SK, Mony P, Jayakumar S, McLaughlin C, Arora P, Kumar R, Bhatia P and Jha P: Prevalence and correlates of herpes simplex virus-2 and syphilis infections in the general population in India. Sexually transmitted infections 2011; Sex Transm Infect 87(2): 94-100, 2011.

25 Gentile I, Zappulo E, Bonavolta R, Maresca R, Riccio MP, Buonomo AR, Portella G, Vallefuoco L, Settimi A, Pascotto A, Borgia $\mathrm{G}$ and Bravaccio C: Prevalence of herpes simplex virus 1 and 2 antibodies in patients with autism spectrum disorders. In Vivo 28(4): 667-671, 2014.

26 Gentile I, Talamo $M$ and Borgia G: Is the drug-induced hypersensitivity syndrome (DIHS) due to human herpesvirus 6 infection or to allergy-mediated viral reactivation? Report of a case and literature review. BMC Infect Dis 10: 49, 2010.

27 Sundstrom P, Juto P, Wadell G, Hallmans G, Svenningsson A, Nystrom L, Dillner $J$ and Forsgren L: An altered immune response to Epstein-Barr virus in multiple sclerosis: A prospective study. Neurology 62(12): 2277-2282, 2004.

28 Gentile I, Bonadies G, Buonomo AR, Minei G, Borrelli F, Foggia M, Chiurazzi F and Borgia G: Resolution of autoimmune thrombocytopenia associated with raltegravir use in an HIVpositive patient. Platelets 24(7): 574-577, 2013.

29 Mahic M, Mjaaland S, Bovelstad HM, Gunnes N, Susser E, Bresnahan M, Oyen AS, Levin B, Che X, Hirtz D, ReichbornKjennerud T, Schjolberg S, Roth C, Magnus P, Stoltenberg C, Suren P, Hornig M and Lipkin WI: Maternal immunoreactivity to herpes simplex virus 2 and risk of autism spectrum disorder in male offspring. mSphere 2(1): 2, 2017.

30 Koren A, Tasher D, Stein M, Yossepowitch O and Somekh E: Neonatal herpes simplex virus infections in Israel. Pediatr Infect Dis J 32(2): 120-123, 2013.

31 Carter CJ: Susceptibility genes are enriched in those of the herpes simplex virus $1 /$ host interactome in psychiatric and neurological disorders. Pathog Dis 69(3): 240-261, 2013.

Received May 17, 2018

Revised June 16, 2018

Accepted June 19, 2018 